\title{
Del ojo a la mirada: debates sobre el sentido de la vista y las técnicas de observación y registro en la ciencia moderna
}

\author{
(4) Carla Lois \\ CONICET / Instituto de Geografía, Facultad de Filosofía y Letras, Universidad de Buenos \\ Aires, Argentina. \\ Malena Mazzitelli Mastricchio \\ CONICET / Universidad Autónoma de Entre Ríos, Argentina.
}

Recibido: 22 de diciembre de 2017. Aceptado: 31 de agosto de 2018.

\begin{abstract}
Resumen
En este trabajo, abordaremos los debates sobre el sentido de la vista y las técnicas de observación en el registro en la ciencia moderna, con alusiones al impacto que tuvieron en el campo de los saberes geográficos y en los modos de registrar el espacio geográfico. $\mathrm{El}$ argumento central es que las técnicas de observación pasaron de estar pensadas predominantemente a partir del estudio del funcionamiento del ojo, la perspectiva, la óptica y los instrumentos que modifican la visión natural, a concentrarse en las técnicas de interpretación de las imágenes producidas con tales dispositivos y en las técnicas de comunicación de sentidos, de conocimiento sobre el espacio geográfico y de imaginarios geográficos. Estas cuestiones serán abordadas a partir de tres ejes: a) la relación entre la observación natural y el desarrollo de la perspectiva; b) el papel de los instrumentos en la observación y registro del mundo sensible, incluyendo las ideas que postulan que el ojo humano es también un instrumento, y c) el lugar de la técnica en la problematización del acto de ver y la construcción cultural de la mirada.
\end{abstract}

PALABRAS CLAVE: IMAGEN TÉCNICA. OBSERVACIÓN CIENTÍFICA. MIRADA. INSTRUMENTOS CIENTÍFICOS.

\section{From the eye to the gaze: debates about the sense of sight and techniques of observation and recording in modern science}

\begin{abstract}
In this article, we will address the debates about the sense of sight and the techniques of observation in the register of modern science, with allusions to the impact they had in the field of geographical knowledge as well as in the ways of registering the geographical space. The main argument is that the techniques of observation went from being
\end{abstract}


predominantly thought through the study of the functioning of the eye, perspective, optics and instruments that modify the natural vision, to the study of the techniques of interpretation of images produced with devices and techniques of communication of senses, of knowledge about geographic space and of geographic imaginaries. These issues will be addressed on three axes: a) the relationship between natural observation and the perspective development; b) the role of instruments in the observation and recording of the sensitive world, including ideas that postulate that the human eye is also an instrument, and c) the place of the technique in the problematization of the act of seeing and the cultural construction of the gaze.

KEYWORDS: TECHNICAL IMAGES. SCIENTIFIC OBSERVATION. GAZE. SCIENTIFIC INSTRUMENTS.

PALAVRAS-CHAVE: ARTE. OBSERVAÇÃO. OLHAR. CIÊNCIA.

\section{Introducción}

En el contexto de las reflexiones epistemológicas que se multiplicaron desde la llamada Revolución Científica ${ }^{1}$ en adelante, hubo varias polémicas acerca, por un lado, de la naturaleza de las imágenes y de las técnicas utilizadas para generarlas; y por otro, de la utilidad que pudieran tener las imágenes para producir conocimiento.

Fue, además, un tiempo en que se construyeron instrumentos que modificaron radicalmente la capacidad y los modos de ver. Denis Cosgrove sintetiza magistralmente por qué los instrumentos de visión son la imagen metonímica por excelencia de la racionalidad científica:

Desde el 1600 la invención y el rápido desarrollo de la tecnología de las lentes en los microscopios y telescopios abrió nuevos espacios para la visión humana y se recibieron con entusiasmo como instrumentos de ayuda para pintar y trazar mapas del espacio. Este tipo de tecnología sirvió para aumentar esa identificación entre la observación empírica, el razonamiento matemático y el conocimiento, lo que llamamos revolución científica (2002: 63-89).

Esta acertada observación de Denis Cosgrove nos sirve para encuadrar las problemáticas aquí abordadas con términos más afines a este trabajo: las periodizaciones clásicas que separan la Modernidad Temprana (ya sea tomando de punto de partida el descubrimiento de América o, más genéricamente, el Renacimiento) de la Edad Moderna (haciendo hincapié en la Revolución Científica, la Ilustración y la Revolución Francesa) han sido puestas en cuestión en el campo de la historia de las ciencias y, en cambio, se acepta genéricamente la emergencia de una episteme moderna (Foucault, 1968) que no ha sido monolítica y que ha dado lugar a desarrollos que tomarán más tarde, en el siglo XIX, la forma de disciplinas científicas. Desde este enfoque, se entiende que el impacto del desarrollo de los instrumentos tampoco ha sido lineal sino que, por el contrario, la incorporación de aparatos y dispositivos visuales tuvo adeptos y detractores que convinieron (a veces debatiendo entre ellos y a veces, simplemente, ignorándose mutuamente). Esto hace que resulte imposible trazar una genealogía cronológica ni continua (menos aún una historia completa, algo

1 Para una revisión crítica y rigurosa sobre la concepción historiográfica y política de la idea de Revolución Científica, véase Shapin, 2000. 
que escapa el formato de un artículo) de los procesos aquí analizados. Para sortear esta dificultad, se han escogido hitos o episodios (Lois, 2014) sintomáticos del proceso sobre el que intentamos dar cuenta.

Ese proceso tiene un eje transversal que atraviesa el periodo definido y enlaza episodios que, aunque separados en tiempo y espacio, resultaron complementarios en la formulación de prácticas científicas. Ese eje se basa en la siguiente premisa: los nuevos instrumentos dieron lugar a nuevas imágenes que no sólo alteraron los tamaños de los objetos observados sino que, literalmente, los hicieron visibles de maneras que eran inéditas. Además de los dos casos más estudiados y mencionados -el microscopio y el telescopio- el desarrollo de instrumental dio lugar a nuevas técnicas de observación y modificó las prácticas de producción de conocimiento en diversos campos. Por ejemplo, desde finales del siglo XIX, la técnica conocida como rayos equis (en rigor, la radiación electromagnética) atraviesa cuerpos opacos (como los tejidos corporales) y permite obtener imágenes en películas fotográficas de los huesos traspasando los tejidos y dando acceso a algo que antes sólo se podía hacer mediante una disección. Sin embargo, la innovación técnica no fue suficiente para modificar las prácticas científicas: el uso de los rayos-X requirió una reformulación de la idea misma de cuerpo humano, requirió crear un referente para que esa imagen fuera legible y portadora de información útil más que un conjunto de sombras grises que mostraba capas superpuestas de tejidos. Sólo a partir del trabajo sutil de dar forma conceptual a un objeto que encaje con cierta tecnología de visualización novedosa (como eran los rayos-X), y viceversa, fue posible que las imágenes fueran leídas para buscar respuestas sobre esos objetos, es decir, fue posible que las imágenes refirieran a ellos y lograran significarlos.

Es decir, las técnicas de observación y los instrumentos forman parte intrínseca de los modos de producir conocimiento, y su desarrollo técnico, su aceptación social y su capacidad de registrar datos y organizar información estuvieron en el centro de un debate que todavía está abierto: ¿̇cómo funciona la vista en las técnicas de observación en el trabajo científico? Las posturas varían entre dos extremos: algunos resistieron el uso de instrumentos y abogaron por seguir confiando en los sentidos (la visión, concretamente) como medio para acceder al mundo natural; otros afirmaron que los instrumentos y la técnica deben, en cierto sentido, reemplazar al observador porque mientras que nuestros sentidos generan impresiones engañosas, los instrumentos son algo así como un nuevo sentido de asombrosa precisión.

En este trabajo, abordaremos los debates sobre el sentido de la vista y las técnicas de observación en el registro en la ciencia moderna, con alusiones al impacto que tuvieron en el campo de los saberes geográficos y en los modos de registrar el espacio geográfico. $\mathrm{El}$ argumento central es que las técnicas de observación pasaron de estar pensadas predominantemente a partir del estudio del funcionamiento del ojo, la perspectiva, la óptica y los instrumentos que modifican la visión natural, a concentrarse en las técnicas de interpretación de las imágenes producidas con tales dispositivos y en las técnicas de comunicación de sentidos, de conocimiento sobre el mundo sensible.

Estas cuestiones serán abordadas a partir de tres ejes: a) la relación entre la observación natural y el desarrollo de la perspectiva; b) el papel de los instrumentos en la observación y registro del mundo sensible, incluyendo las ideas que postulan que el ojo humano es también un instrumento, y c) el lugar de la técnica en la problematización del acto de 
ver y la construcción cultural de la mirada. Los casos seleccionados para desarrollar el argumento son episódicos, sintomáticos de momentos en los que las técnicas de observación y registro eran objeto de debate, innovación, modificaciones e incertidumbre. Por lo tanto, los episodios históricos serán revisadas a la luz de perspectivas historiográficas que explican el proceso epistémico que desplazó tanto el desarrollo instrumental como las reflexiones sobre sus usos, desde el acto físico de la visión a la práctica del mirar.

\section{La vista, la observación "natural" y el desarrollo de la perspectiva}

En la época que, genéricamente, se ha denominado la Ilustración, la visión se fue consolidando como una de las estrategias privilegiadas en la construcción del conocimiento (en particular de aquello que se llamaba mundo natural y que luego se consideró geográfico). En primer lugar, porque el sentido de la vista parecía garantizar la constatación de la existencia del mundo material, a diferencia del tacto, que otrora había sabido ocupar ese papel: en efecto, el sentido del tacto formó parte integrante de las teorías clásicas de la visión en los siglos XVII y XVIII. "La disociación de tacto y vista que le sigue tiene lugar en el marco general de una 'separación de los sentidos' y de una configuración industrial del cuerpo que tiene lugar durante el siglo XIX. Una vez que el tacto dejó de ser un componente conceptual de la visión, el ojo se desligó de la red referencial encarnada en la tactilidad e inició una relación subjetiva con el espacio percibido" (Crary, 1990: 39). Esta idea de la preponderancia de lo visual reposaba en una serie de presunciones epistemológicas que provenían desde, al menos, la Modernidad Temprana: era un lugar común entre los escritores del Renacimiento, Galileo incluido, la importancia de apartarse de los libros para estudiar las cosas en sí mismas, para salir a mirar y leer el libro de la naturaleza que tenemos abierto delante de nuestros ojos. ${ }^{2}$

En segundo lugar, la vista y la visión hacían posible los procesos de abstracción, reflexión y representación que volvían comprensible a ese mundo a través de la producción de imágenes. Hacia fines del siglo XVIII todavía suponían que la observación ocular y, más tarde, el registro disciplinado de esas observaciones garantizaba el conocimiento fiel de lo observado. Ese registro disciplinado consistió en números (obtenidos en prácticas de mediciones de todo tipo) y, sobre todo, en diversos gráficos que se fueron ensayando para representar lo observado y la experiencia de la observación, desde imágenes figurativas o esquemáticas, hasta mapas, árboles, diagramas y otros, ${ }^{3}$ ya que:

(...) a la mente le es necesario comprender, pero no puede hacerlo a no ser que proyecte lo que ve en modelos manejables. Los primeros modelos son los que sugiere la apariencia misma. Aquí el sentido de la vista intenta la configuración

2 La ciencia moderna siguió a Galileo en su convicción de que el libro de la Naturaleza está escrito en el lenguaje matemático y que sus caracteres son triángulos, círculos y otras figuras geométricas: "La filosofía está escrita en ese libro enorme que tenemos continuamente abierto delante de nuestros ojos (hablo del universo), pero que no puede entenderse si no aprendemos primero a comprender la lengua y a conocer los caracteres con que se ha escrito. Está escrito en lengua matemática, y los caracteres son triángulos, círculos y otras figuras geométricas sin los cuales es humanamente imposible entender una palabra; sin ellos se deambula en vano por un laberinto oscuro", Galileo Galilei (2010: 27).

3 La bibliografía sobre este tema es sumamente amplia e incluye tanto aproximaciones teóricas como estudios de caso. Aquí mencionamos sólo algunos de los textos que resultaron más inspiradores para las reflexiones de este artículo: Tufte, (1990); Seymour, (2007); Moretti, (2005 [2007]); Bredekamp, (2008) y Deleuze, (2007). 
más simple compatible con la situación estimulante dada. Esta interacción entre las exigencias del objeto y las tendencias en el observador, se repite a niveles superiores del entendimiento (Arnheim, 1960: 291).

La hegemonía de la visión como sentido noble coincidió con los debates y las teorías sobre la óptica y la visión. ${ }^{4}$ Los mecanismos de la visión eran analizados como luego lo sería la fotografía: como un instrumento ajeno al cuerpo humano que capta un mundo exterior de manera directa.

Desde un enfoque severamente criticado, James Gibson (1950) formuló una teoría de la percepción visual directa sobre la premisa general de que la percepción directa no está basada en la experiencia de sensaciones sino en la recolección de información ${ }^{5}$ aunque no necesariamente quiere decir sin mediaciones, es decir, sin instrumentos. De hecho, también usó la expresión percepción visual directa para referir a la observación exclusiva de la imagen que produce el instrumento. Por ejemplo, en repetidas ocasiones ilustró su postura con una anécdota: se cuenta que Alexander von Humboldt se perdió de ver un eclipse de sol por no levantar la vista del sextante y que nunca se arrepintió de ello ni se lo reprochó a sí mismo porque lo que estaba en juego era la ubicación exacta de un punto que quedaría fijado para siempre en los mapas del mundo, y porque la realidad para Humboldt, el campo de percepción de fenómenos como un eclipse, era menos real que su ciencia. Entonces "descubrimos en cambio que la observación directa, lejos de ser una mera recolectora, constituye una exploración llevada a cabo por la mente, que busca e impone la forma" (Arnheim, 1960: 291).

Desde la segunda mitad del siglo XVII, muchos filósofos naturales entusiasmados en la confianza que les inspiraba la observación directa (i.e. ocular), a menudo habían recurrido al dibujo para registrar sus observaciones e incluso para sintetizar, ilustrar o ejemplificar sus disertaciones tanto en presentaciones orales como en artículos publicados en revistas especializadas. En ocasión del terremoto en Calabria (1783), la Academia de Ciencias napolitana envió un grupo de hombres a levantar registros visuales de los efectos devastadores del sismo, que retrataron el paisaje siguiendo convenciones pictóricas que ya tenían una consolidada trayectoria en la descripción visual del paisaje (Keller, 1998: 129-130).

En efecto, el acto de ver/mirar y el de producir imágenes están íntimamente ligados: ciertas maneras de ver conllevan a producir cierto tipo de imágenes y, viceversa, cierto tipo de imágenes legitimadas en un campo científico orientan la mirada y la observación del sujeto que mira. Por otra parte, en los libros de ciencias las imágenes no son sólo ilustraciones sino que ellas mismas construyen objetos de análisis, o en términos de Horst Bredecamp, "la imagen no es un derivado ni una ilustración sino un medio activo del proceso de pensamiento" (Bredekamp, 2005 citado en Moxey, 2009: 16). En relación con las ciencias físicas y biológicas, Michael Lynch afirmaba que la importancia de los materiales visuales radica en que permiten transformar sistemáticamente especímenes en datos observables y matemáticamente analizables (Lynch, 1990). Además, insistía

4 Sobre la historia de las teorías de la visión véase Ings, 2008.

5 En un mismo libro coordinado por Noë, y Evan (2002) puede encontrarse tanto el enfoque de Gibson como una respuesta crítuca: Fodor y Pylshyn, (2002), Vision and Mind. Selected Readings in the Philosophy of Perception. Massachussets Insitute of Technology, Massachussets. 167-228. 
en que más allá del carácter representacional que pueda atribuírseles, esas imágenes elaboradas con el objetivo de hacer cognoscible científicamente un objeto implican, a su vez, un objeto independiente y logran simultáneamente una representación gráfica de la materialidad del objeto. En este sentido, la cuestión clave no consiste en examinar cómo las propiedades objetivas se corresponden con los dispositivos gráficos a través del aislamiento y ordenamiento de tales propiedades sino que, más bien, habría que preguntarse cómo las propiedades gráficas se relacionan con ese objeto y cómo es que proponen encarnarlo. Su suposición es que la ciencia construye sus objetos a partir de lo que los dispositivos gráficos revelan (Lynch, 1990).

Incluso, en ciertas ocasiones, esas imágenes son el resultado de la observación de campo pero no para retratar lo visto en el terreno sino para formular teorías explicativas sobre ello. Por ejemplo, en el campo de las ciencias de la Tierra, en el siglo XVIII, los filósofos naturales se habían visto ante la necesidad de registrar los efectos y al mismo tiempo explicar las causas de ciertos movimientos sísmicos (algunos de ellos, de gran impacto, como el terremoto de Lisboa de 1755), y para ello también recurrieron a gráficos e imágenes. La competencia por definir las causas del terremoto de Lisboa popularizó el uso de gráficos entre los interesados en ese campo del saber, tanto por su capacidad didáctica como por la posibilidad de dar visibilidad a lo que hasta entonces resultaba invisible y, por tanto, todavía más enigmático (Keller, 1998). Sin embargo, la naturaleza de los fenómenos a representar (las erupciones volcánicas, por ejemplo, son fenómenos impredecibles, de corta duración, de difícil observación y, durante mucho tiempo, de complicado registro) hacía que sólo pudieran representarse sus efectos. Entonces las imágenes resultaban fundamentales para analizar e hipotetizar sobre las causas de tales fenómenos, luego de esa ocurrencia tan efímera y escurridiza a los protocolos de observación científica. Literalmente: las imágenes eran el terreno de observación, el único trabajo de campo posible.

Estos modos de producir y analizar imágenes para ver lo real es lo que Ivins llamó racionalización de la mirada:

(...) la ciencia y la tecnología han progresado en relación directa con la capacidad del hombre de inventar métodos gracias a los cuales los fenómenos que no podrían ser conocidos, sino que por los sentidos del tacto, del gusto y del olfato, han podido ser visualmente reconocidos y medidos (1985: 37).

Lo mismo puede ser dicho desde el ángulo del observador que racionaliza sus sentidos: "El concepto del 'observador' implica por consiguiente no sólo un ojo incorporado y espectacularizado sino también que sus operaciones se han sujetado a una compleja racionalización" (Silverman, 1996: 141).

El desarrollo de la perspectiva tuvo un fuerte impacto en las técnicas de representación gráfica del espacio, especialmente porque sirvió para crear imágenes realistas que permitían representar (y reconocer) diversos planos y la profundidad de campo de manera análoga a la experiencia sensible del ojo humano. Si bien este asunto ha sido larga y ampliamente tratado en la historia del arte, ${ }^{6}$ la reflexión sobre los efectos que tuvieron las imágenes de perspectiva lineal en las ciencias es bastante más

6 Remitimos al clásico trabajo de Edgerton, 1975. 
reciente y, por cierto, bastante sugerente. Por ejemplo, Bruno Latour afirmó que la racionalización que tuvo lugar durante lo que se conoce como revolución científica no fue una racionalización de la mente, ni del ojo, ni de la filosofía, sino de la vista, porque gracias a la perspectiva lineal, todo objeto -sin importar desde qué distancia o ángulo es visto- puede ser transformado en imagen y, por tanto, transferido o traducido para obtener el mismo objeto en otro tamaño o visto desde otra posición. En esa traducción las propiedades internas de ese objeto no se modifican. Es en este sentido que la perspectiva fue un determinante esencial de la ciencia y la tecnología porque creaba cierta "consistencia óptica" (Ivins, 1985: 30-37) que permitía establecer analogías de formas y tamaños entre objetos reales y las imágenes que las comunidades científicas hacían de ellos. La vista como instrumento para componer el ojo perspectiva que ensayaba modos de mostrar y dar a ver ese mundo mensurado. En este sentido, el ojo era un dispositivo de racionalización que tornaba comprensible y comunicable los hechos de la vista.

En el caso del espacio geográfico, el desarrollo de la perspectiva fue clave tanto para representar el espacio con la profundidad de planos y para desarrollar proyecciones cartográficas, como para establecer vínculos sensibles entre los sujetos y su espacio, ya que las tres dimensiones de la geometría euclideana en las que se basa la perspectiva:

(...) pueden fácilmente concebirse de modo intuitivo por referencia a nuestro cuerpo y a su posición en el espacio: la verticalidad es la dirección de la gravedad y de la posición del pie; la segunda dimensión, horizontal, sería la de la línea de los hombros, paralela al horizonte visual que hay ante nosotros; la tercera dimensión, finalmente, es la de la profundidad, correspondiente al avance del cuerpo en el espacio (Aumont, [1990] 2013: 40-41).

En tanto la perspectiva albertiana disciplinaba o desnudaba los principios geométricos de la medición e inventaba una nueva forma de naturalismo, la triangulación, las proyecciones cartográficas y las fórmulas de escalas miniaturizantes aseguraban los principios geométricos de la superficie terrestre.

En el siglo XIX se impone el ideal epistemológico de objetividad en las ciencias, entendida como el modo de representar exactamente lo que se ve (y que se asume es visible y se ve simplemente porque existe en una realidad externa al observador) sin permitir que intervenga la subjetividad de quien observa. Se abre un nuevo debate: cómo se mira y cómo se registra lo que se mira para producir saberes objetivos. En el caso de las imágenes, la propia idea de objetividad fue mutando a lo largo del tiempo y atravesó distintas etapas. En términos generales, se distinguen tres épocas: verdadera naturaleza (truth-to-nature, que se instala a fines del siglo XVIII), objetividad mecánica (en el siglo XIX) y "juicio entrenado" (Daston y Galison, 1992: 42-43).

En la primera etapa, las imágenes representaban un ejemplar botánico ideal que representa a un tipo genérico de su clase, con sus propiedades representadas según un promedio y no según las particularidades del modelo tomado para dibujar la planta en cuestión (por ejemplo, se eliminaban magulladuras u otros defectos). Se buscaba rescatar la estructura, lo constante y estable, lo arquetípico. Para ello era imprescindible la participación de un savant que supiera mirar de ese modo. 
La segunda etapa, que se inicia en la segunda mitad del siglo XIX, coincide con la aparición de diversos instrumentos de mensura y registro, entre los que se destaca la fotografía. En ese contexto, la imagen ideal no debía ser intervenida (simplificada, idealizada, embellecida) y debía ser producida por un instrumento mecánico que se interponga entre el objeto y el sujeto para garantizar la falta de contaminación subjetiva en la imagen, y seguir un protocolo preestablecido.

En la última etapa, se admite que para lograr una imagen objetiva debe participar el juicio entrenado del científico para eliminar ruidos innecesarios y para limpiar la imagen final, pero sin aspiraciones a construir un ideal, e incluso, remarcando las variantes.

En el proceso de búsqueda de objetividad, los instrumentos y los protocolos de observación adquirieron una primacía fundamental.

\section{Los instrumentos de observación, registro del mundo sensible y las imágenes}

En la historiografía de la historia de la ciencia, la cuestión técnica y la invención de instrumentos han ocupado un lugar destacado, a menudo desapegadas de las necesidades culturales, políticas, económicas e incluso personales que motivaron su desarrollo y su posterior aceptación social como parte de un protocolo científico de una época dada. Sin embargo,

(...) los dispositivos ópticos ${ }^{7}$ en cuestión, de manera significativa, son puntos de intersección en los que los discursos, filosóficos y estéticos se solapan con técnicas mecánicas, requerimientos institucionales y fuerzas socioeconómicas (Crary, 1990: 24).

Los viajeros curiosos e ilustrados del siglo XVII se interesaban más por las cosas raras, las singularidades locales y los fenómenos extraños que veían y registraban. Hasta entonces, la regularidad suprema del mundo había sido atribuida a la deidad y su representación era dejada a las matemáticas y otras ciencias (mientras que el mundo mundano de la experiencia ordinaria quedaba para las artes y los oficios, que apenas podían poner un orden muy limitado). Pero esa epistemología fue reemplazada por "un nuevo régimen de conocimiento, basado en prácticas empíricas y en el uso de instrumentos, comenzó a seguirse como desafío a las prácticas observacionales anteriores. Este tipo de producción de conocimiento natural floreció a lo largo del siglo XVIII, tanto en los laboratorios de los filósofos naturalistas como en el trabajo de campo de viajeros de ultramar, en el terreno de los relevamientos topográficos y en las exploraciones de las montañas" (Bourguet, Licoppe y Sibum 2002: 3).

7 Para interpretar la expresión dispositivos ópticos nos apoyamos en la categoría foucaultiana dispositivo, que Deleuze delineaba en los siguientes términos: "Las dos primeras dimensiones de un dispositivo, o las que Foucault distingue en primer término, son curvas de visibilidad y curvas de enunciación. Los dispositivos son (...) máquinas para hacer ver y para hacer hablar (...). Cada dispositivo tiene su régimen de luz, la manera en que ésta cae, se esfuma, se difunde al distribuir lo visible y lo invisible, al hacer nacer o desaparecer al objeto que no existe sin ella" (1999: 16). 
El desarrollo de nuevos instrumentos fue dando lugar a nuevos tipos de imágenes que no sólo alteraron los tamaños de los objetos sino que, literalmente, los hicieron visibles de maneras que eran inéditas y que requirieron nuevas habilidades para producir, ver e interpretar las imágenes que se obtendrían con tales instrumentos. Junto con la aparición de nuevos dispositivos para ver surgieron nuevas dificultades de comunicación e interpretación (como el caso mencionado en la Introducción sobre los rayos-x). Por eso, "lejos de constituir simples prótesis del ojo, ellos [los dispositivos técnicos aplicados a la visión] proponen una nueva visión del mundo" (Sicard, 1998: 61) y crean nuevas formas de visión humana. En otros términos: había que re-aprender a ver, caso contrario las nuevas imágenes quedarían mudas ante la interpelación de la mirada.

El inglés Robert Hooke (1635-1703), que desde 1662 era el director de la Royal Society de Londres, no sólo desarrolló el microscopio sino que además se embarcó en la tarea de producir un sofisticado atlas del mundo natural microscópico, publicado en 1665 (Martyn y Allestry, 1989), con detalladas ilustraciones y descripciones. El propio Hooke pensaba que el microscopio era un dispositivo prosthetic capaz de restituir la original e incorrompida visión de la naturaleza que tiene el hombre, de manera similar a otros científicos de mediados del siglo XVII que estaban confiados en que la lente microscópica demostraría la "veracidad de la filosofía mecánica" (Schickore, 2007: 15).

Al mismo tiempo que se desarrollaban lentes cada vez más sofisticadas para ver las estructuras microscópicas invisibles al ojo natural, se hicieron esfuerzos similares para ver objetos lejanos en el espacio interestelar. El cuadrante mural del Tycho Brahe (1546-1601) permitía cinco aumentos; pocos años más tarde, la lente pulida de Galileo Galilei (convexa como objetivo con una lente ocular cóncava) alcanzaba los veinte aumentos. Le siguieron el telescopio aéreo de Christiaan Huygens (1629-1695) y el telescopio reflector de Isaac Newton (1643-1727) e incluso el reflector parabólico de William Herschel (1738-1822). Y así sucesivamente, la carrera para lograr instrumentos que permitieran observar el cielo no dejó de buscar acceder -al menos a través de imágenes - a objetos cada vez más inaccesibles. Sin embargo, los instrumentos no sólo crearon imágenes transparentes y las formas de usar los instrumentos requirieron del entretenimiento en nuevas formas de mirar, sino también, de nuevas formas de pensar el acto mismo de la observación, así como la naturaleza misma de lo observable. El mismo Herschel ha contado que:

Cuando, con el tiempo, me metí en la cuestión de la astronomía, me decidí a no aceptar nada que estuviera basado solo en la fe sino en aquello que hubiera visto con mis propios ojos, incluso aquello que otros ya habían visto con sus propios ojos antes que yo. Ver es, en cierto sentido, un arte que debe ser aprendido. Para hacer que una persona logre ver con semejante poder [se refería al telescopio que él mismo había inventado] es casi lo mismo que pedirle a alguien que ejecute una fuga de Haendel en el órgano sólo después de haberla escuchado. Muchas veces he pasado noches enteras practicando el arte de ver, y sería extraño que no haya adquirido cierta destreza con semejante practica constante (citado en Turchi, 2004: 227).

William Herschel había comenzado a interrogarse sobre las limitaciones del poder del telescopio como dispositivo para penetrar en el espacio según la apertura de sus lentes, el brillo absoluto de los cuerpos celestes, la distancia a la que se hallaban respecto del observador y, también, el ojo del observador (Schickore, 2007). Y, a su vez, el 
desarrollo técnico de cada uno de estos dispositivos en instrumentos progresivamente más pequeños, portables, manejables y resistentes, llevó también al desarrollo de nuevas prácticas y a la ampliación de sus usos, por ejemplo, fuera del laboratorio y en terrenos más hostiles que los de las instituciones científicas (Daston y Galison 1992).

¿Cómo debían usarse las imágenes producidas con esos dispositivos? ¿Qué estatus epistemológico tendrían? Para René Descartes, las imágenes no eran el único estímulo capaz de excitar el pensamiento, ya que el mismo efecto producían los signos y las palabras que de ningún modo se parecen ni asemejan en forma o apariencia a las cosas que ellas significan (Pomián, 1998). René Descartes consideraba que los instrumentos eran la materialización de teorías. Incluso cuando el telescopio había sido desarrollado, según él, gracias a una acción fortuita y accidentada, su aparición suministraba preciosos resultados de observaciones basados en las leyes de la óptica y de la intuición intelectual.

David Hume, al contrario, sostenía que nuestro conocimiento consiste apenas en las relaciones que establecemos entre impresiones e ideas (incluso por hábito y repetición más que por la fuerza de algo factual) (Pomián, 1998). Desde la perspectiva de David Hume, los instrumentos eran sólo extensión de nuestros sentidos y nos permitían nuevas sensaciones, pero no lograban desplazar la mirada humana del centro del proceso de conocimiento. Emmanuel Kant, que concentró sus reflexiones sobre el espacio en nociones ancladas en la física, las matemáticas y las ciencias naturales, le atribuía a la mente la espontaneidad de integrar lo que le es dado a través de los sentidos con las síntesis intelectuales construidas, en una jerarquía de niveles que iban desde las formas de sensibilidad hasta los principios de la razón pura.

El perfeccionamiento de los instrumentos fue alentando crecientemente el deseo de exactitud del que se derivaba, explícita o implícitamente un juicio de verdad. Cuando Anne-Marie Godlewska analiza la relación entre mapa, texto e imagen sostiene que "si algo podía ser representado con precisión (precision), detalle o exactitud (accuracy), claramente tenía el valor de una verdad" (1995: 9).

Cuando los instrumentos utilizados para repetir el mismo experimento eran capaces de producir los mismos datos una y otra vez se los consideraba precisos. En el campo de la observación visual científica y precisa, los microscopios se transformaron en "emblemas de precisión" (Schickore, 2007: 79), una "extensión y perfeccionamiento de la visión humana" (Schickore, 2007: 5), sobre todo cuando se le adjuntó un micrómetro y la posibilidad de medir potenció su uso en diversos dominios (Schickore, 2007).

También en la cartografía, "la precisión se convirtió en el nuevo talismán de la autoridad" (Harley, 2001: 107), ya que, en ese contexto, el relevamiento del terreno y su inscripción en mapas estaba mediada por instrumentos, lenguajes de inscripción y operaciones matemáticas. Los principios de las proporciones en los que se basaba la escala cartográfica, que establece una correspondencia matemática entre las medidas del mapa y las medidas del terreno o de lo real, sancionaban una relación precisa $y$ exacta entre la imagen mapa y su referente empírico, lo que ha contribuido a afianzar el principio de mímesis del que los mapas parecen parasitar su carácter de verdad. Esa proporcionalidad garantizaba la consistencia óptica de la que hablaba Ivins en tanto hacía posible cálculos que podían materializarse en prácticas espaciales concretas (cálculos de distancias, de superficies, etc.). 
El problema es que progresivamente, la mayor precisión que se lograba con el perfeccionamiento de los dispositivos de medición, llevó a pensar que se podía alcanzar $-o$, al menos, llegar muy cerca de- la exactitud; mientras que la primera refiere a la dispersión del conjunto de valores obtenidos de mediciones repetidas de una magnitud (cuanto menor es la dispersión mayor la precisión), la exactitud corresponde a cuán cerca del valor real se encuentra el valor medido. Y esas concepciones, algo ambiguas, permeaban en el modo de valorar los instrumentos y el papel que cumplía la técnica en la aproximación a una verdad.

La masificación del uso de la fotografía en las ciencias introdujo significativos cambios y adaptaciones de estas concepciones en las prácticas de producción de conocimiento que, si bien variaban según las distintas disciplinas, compartían algunos rasgos en común. Se sabe que reforzó la función de índice de los registros gráficos (Dubois, 1983) y potenció el efecto de realismo. Entre ellos, planteó la temporalidad del ver: el momento de la captura de la imagen y los momentos de observación de la imagen. Pero, sobre todo, a pesar de que Benjamin le ha atribuido a la reproductibilidad técnica la pérdida del aura que tenían las imágenes únicas e irreproducibles, en las ciencias ese aura se vio fortalecida por la mecanicidad de la toma fotográfica, divorciada de un ojo humano -que es reemplazado por una lente que captura la luz e imprime la realidad en una placa-:

Existe una suerte de consenso de principio que pretende que el verdadero documento fotográfico rinda cuenta fiel del mundo. Se le ha atribuido una credibilidad, un peso real absolutamente singular. $Y$ esta virtud irreductible del testimonio descansa en la conciencia que se tiene del proceso mecánico de producción de la imagen fotográfica, de su modo específico de constitución y de existencia: el automatismo de su génesis técnica (Benjamin, 2015: 12).

La "esencia mimética" (Dubois, 1983: 20) entre la foto y su referente, que marcaba la clave de interpretación de los objetos fotográficos hacia fines del siglo XIX, privilegiaba la noción de semejanza entre ambos, en tanto el ojo natural podía percibir analogías entre la foto y lo real. Esta dualidad de la experiencia visual (que no termina de desdoblar la experiencia visual sujeto-objeto real y sujeto-objeto fotografiado) está en la base del efecto de realismo de la fotografía, que se transfiere como experiencia de constatación de la existencia del objeto fotografiado. Además, una imagen mecánica necesariamente tomada por alguien que estuvo ahí, certifica la accesibilidad -cuanto menos, visual- a una parte del mundo sensible.

La foto no solo aporta realismo sino que también supone cierta objetividad, entendida aquí como una distancia prudente entre el objeto representado y el sujeto que mira. Así la foto instala un velo de protección frente a la subjetividad, hace visible una distancia física entre el fotógrafo y lo fotografiado, pero también establece una distancia intelectual respecto de la opinión que expresa la letra escrita así como de las imprecisiones deliberadas o intencionadas del trazo del cartógrafo. Susan Sontag sintetizaba esta idea con estas palabras:

(...) la fotografía tiene poderes que ningún otro sistema de imágenes ha alcanzado jamás porque, al contrario de los anteriores, no depende de un creador de imágenes. Aunque el fotógrafo intervenga cuidadosamente en la preparación y guía del proceso de producción de las imágenes, el proceso 
mismo sigue siendo óptico-químico (o electrónico) y su funcionamiento automático, y los artefactos requeridos serán inevitablemente modificados para brindar mapas aún más detallados y, por lo tanto, más útiles de lo real (1973: 222).

Pero mucho antes que la fotografía, la relación visión-dispositivo-espacio se había puesto en cuestión con la aparición y la divulgación del estereoscopio (tanto para fines científicos como para entretenimiento), un aparato que utilizaba dos lentes para ver dos fotografías casi idénticas pero cada una de ellas monocular y que con el aparato recuperaban su naturalidad. Por eso, "el estereoscopio es inseparable de los debates de principios del siglo XIX sobre la percepción [visual] del espacio, que continuarían irresueltos indefinidamente. ¿Era el espacio una forma innata o algo que se reconocía a través de indicios aprendidos después de nacer?" (Crary, 1990: 157). Lo que revelaba era que la mirada binocular tenía peculiaridades que ponían en cuestión los códigos del espacio monocular y el punto de vista geometrizado que se había impuesto como normal y realista desde el Renacimiento con la generalización del uso de la técnica de la perspectiva y que la fotografía parecía confirmar. ${ }^{8}$

Estas cuestiones remitían a otro debate: cilos instrumentos debían suplir a los sentidos o ser considerados como tales? ¿Los sentidos tenían que ser adiestrados para que funcionaran como instrumentos?

Aunque algunos resistieron el uso de instrumentos y abogaron por seguir confiando en los sentidos como medio para acceder al mundo natural, lo cierto es que el desarrollo de instrumentos es indisociable de las ciencias -e incluso llegaron a ser considerados un sentido más-. En 1878, el psicólogo francés Etienne-Jules Marey, en su obra La Méthode Graphique, afirmaba que hay instrumentos que no sólo a veces reemplazan al observador, y en esas circunstancias llevan a cabo su papel con una superioridad incontestable, sino que también tienen su propio dominio donde nada puede reemplazarlos (Snyder, 2007). Cuando el ojo deja de ver, el oído deja de escuchar, el dejar para sentir, o de hecho cuando nuestros sentidos dan engañosa acaparada, los instrumentes son algo así como un nuevo sentido de asombrosa precisión. Marey también afirmó que los datos producidos por tales instrumentos o máquinas producían, según sus propias palabras, revelaciones: se asumía que los instrumentos penetraban el aparente caos o incluso el cese del movimiento y revelaban un mundo desconocido allí donde los sentidos al desnudo sólo experimentaban anarquía (Snyder, 2007). Es decir, las imágenes permitían ver lo que resultaba indetectable a los sentidos.

Sigmund Freud usó analogías entre instrumentos ópticos (por ejemplo, el cicorcopio y el telescopio), dispositivos de inscripción (por ejemplo, aparatos fotográficos) y sistemas de escritura (por ejemplo, jeroglíficos) (Lenoir, 1998).

Estos debates se inscriben en un contexto de críticas al rol de los instrumentos como medium de acceso a la verdad, que apuntaba a la desacralización de los instrumentos. Más recientemente:

8 Crary atribuye a esta emancipación de la visión que permitía el estereoscopio la causa principal de su desaparición, y la hegemonía de la fotografía: mientras que el primero permitía "simular la estructura anatómica del cuerpo del observador" (Crary, 1990: 169), la fotografía crea un observador disciplinado, más compatible con los valores de la modernidad. 
Un punto central de los estudios científicos ha sido la crítica de todas las caracterizaciones de la relación de la teoría con su objeto que consideran el instrumento científico y el sistema experimental como un medio pasivo y transparente a través del cual alcanza la verdad o la presencia del objeto. El instrumento no es considerado como una mera extensión de la teoría, un mero suplemento, útil para exteriorizar un significado ideal contenido dentro de la teoría. (...) Es a través de nuestras máquinas [dispositivos, diríamos aquí] que se estabilizan las prácticas y simultáneamente una naturaleza susceptible de ser estabilizada (Lenoir, 1998: 6).

John Berger ha propuesto saldar la discusión sobre si el ojo es un instrumento o los dispositivos ópticos son un nuevo sentido señalando los límites de la analogía entre el ojo y la cámara:

La percepción visual humana es un proceso mucho más complejo y selectivo que aquel mediante el cual se imprimen las películas: no obstante, tanto la lente de la cámara como el ojo, debido a su sensibilidad a la luz, registran imágenes a una gran velocidad y de forma inmediata al acontecimiento que tienen delante. Lo que, sin embargo, hace la cámara, y el ojo por sí mismo no puede hacer, es fijar la apariencia del acontecimiento (1998: 70).

Lo que empezaba a imponerse entonces era, también en términos de Berger, la necesidad de reflexionar sobre una variedad de modos de ver.

Luego de casi dos siglos en los que los microscopios parecían poder amplificar todo cada vez con mayor precisión, Joseph Jackson Lister (1786-1869) sugirió que la capacidad de la visión también imponía sus propios límites a la posibilidad de visualización que ofrecerían los mejores microscopios y que ambos -el ojo y el microscopio- funcionaban juntos como un sistema óptico que estaba constreñido por varios factores condicionantes del poder de tal sistema (Schickore, 2007).

\section{La técnica en la problematización del acto de ver y la construcción cultural de la mirada}

Es innegable que

La vista en el mundo moderno es cada vez más prostética, está cada vez más dirigida y se experimenta a través de una amplia serie de ayudas mecánicas a la visión que aumentan las capacidades del ojo por sí solo: lentes, cámaras, proyectores de luz, retículas y telescopios y microscopios (Cosgrove, 2002: 66).

La visión y las técnicas de la visión son ahora dos caras de una misma moneda.

La visión, la vista y el ojo (cuya mecánica debía ser desentrañada, incluso para crear nuevos instrumentos que desplegaran algunos de los mecanismos de producción de imágenes retinales) dejaron de ser sólo un objeto de estudio para la óptica y la física, y empezaron a considerarse en su dimensión fenomenológica, como modos de aproximación, 
comprensión e interacción con el mundo. Jonathan Crary sostiene que a lo largo del siglo XIX se pasó de la óptica geométrica (cámara oscura) a la óptica psicológica (estereoscopio) y que ello fue crucial porque puso "en primer plano la diferencia entre sus propios principios de organización [los de los dispositivos ópticos] y los de la visión humana” y que incluso "lo que está en juego es más que la drástica disyunción del ojo y el aparato óptico: (....) una pérdida de fe en la capacidad del ojo para ver lo que está 'ahí'. Reubicada en las 'inestables fisiología y temporalidad del cuerpo, la visión humana ya no contempla y controla un dominio del cual ella se imagina a sí misma separada" (Silverman, 1996: 138). ${ }^{9} \mathrm{Y}$, más todavía, queda en evidencia que aunque la visión es un proceso eminentemente óptico es también cultural, en tanto debe aprenderse: la visión no es sólo un asunto físico que ocurre independientemente de nuestra voluntad sino que forma parte de un proceso de entendimiento, y por tanto debe aprenderse incorporando métodos y códigos que, generalmente, funcionan en modo inconsciente. En otros términos:

El conocimiento, incluido el conocimiento ambiental, no es natural sino que se aprende, y es subjetivo, ya que es adquirido y desarrollado individualmente por cada sujeto. Se nos enseña a ver, de modo que lo que se conoce está mediado a través de una serie de filtros culturales -sociales, políticos y académicosque refractan la realidad y condicionan o precondicionan lo que vemos. El resultado es que la vista y el conocimiento, la percepción y la concepción están entrelazados y determinados por el sistema de valores -o creencias- en el que nacemos, pasamos nuestros años formativos y al que subsiguientemente nos subscribimos (Pocock, 1981: 386).

Hay cierto consenso en aceptar como punto de partida una distinción básica entre ver y mirar: el primero es un acto físico pasivo que consiste detectar el mundo exterior con el ojo; el segundo, implica un movimiento intencionado de los ojos hacia el objeto de interés.

Ver es la confirmación de una presencia plena de cosas que son visibles con los ojos del cuerpo humano (Guenancia, 2009). En cambio, la mirada no se sostiene sobre cosas reales, en tanto que reales, no es un ver apoyado sobre o aplicado a un objeto sino que es "una reflexión sobre eso que se ve, es un representarse lo que se ve que "se desliza desde el ver y reemplaza (más que modifica) una cosa vista por un objeto representado" (Guenancia, 2009: 175-176), no es el efecto del poder orgánico de la visión sino que "es del orden de la cultura, es una manera de resistir el deslumbramiento de ojo por lo visible" (Guenancia, 2009: 181). Mirar es una práctica, ${ }^{10}$ "es insertar una imagen en el seno de una matriz constantemente cambiante de recuerdos inconscientes" (Silverman, 1996: 11).

Para Goethe ver es un acto pasivo y mirar es un acto activo, direccionado e intencionado, aunque también afirma que uno puede ver sólo lo que conoce (Pocock, 1981). Por eso ver es también entender. Ver es "mucho más que una simple respuesta de los sentidos, es decir algo más que la huella pasiva y neutra de las imágenes formadas por la luz en la retina del ojo" (Cosgrove, 2002: 66).

9 Según Crary, la resistencia a aceptar esa falta de realismo o, en palabras de Ivins, consistencia óptica entre la imagen o lo visto habría condenado definitivamente a la caída en desuso de las prácticas de visión estereoscópicas (a excepción de algunos usos específicos) y, por consiguiente, a la paulatina desaparición del dispositivo mismo (citado en Silverman, 1996: 139).

10 Para una revisión general de esta idea, véase la colectánea Sturken y Cartwright (2001). 
Sin embargo, ver es también un acto cultural y, como tal, está culturalmente condicionado en varios aspectos: está atravesado por filtros sociológicos, políticos, académicos, familiares, apócales, educativos, lingüísticos, morales, etc.; por capacidades subjetivas del observador -físicas, emocionales, experienciales, cognitivas, etc.-; por las tecnologías de la visión -implicadas en la elaboración de la imagen o aplicadas por el observador, o ambas-, y también por las disposiciones de la mirada -observación, mirada fugaz, reconocimiento, intuición, etc.-. Al analizar esos filtros emerge la existencia de un sujeto que mira, observa, registra. El concepto de observador problematiza el acto de ver, reconoce la agencia del sujeto. Pero, lejos de ese ideal de emancipación, el sujeto que mira también está afectado culturalmente:

La mirada está bajo presión cultural a aprehender el mundo desde un punto de vista preasignado (...). La mirada es exhortada desde muchos lados a percibir y afirmar sólo lo que en general pasa es tomado por "realidad". Su subjetividad se ve socavada por todas aquellas formas de reconocimiento por las que se crea (Silverman, 1996: 11).

George Didi-Huberman analiza la posibilidad de pasar del ver al mirar, cómo un acto óptico se transforma en una experiencia subjetiva:

Tal vez cuando vemos algo que de improviso nos toca, no hagamos otra cosa que abrirnos a una dimensión esencial de la mirada, según la cual mirar se convertiría en el juego asintótitco de lo cercano (hasta el contacto, real o fantasmático) y lo lejano (hasta la desaparición y la pérdida, reales o fantastmáticas (Didi- Huberman, 2010: 105).

Cuando pasamos del ver al mirar, cuando pensamos en el sujeto que mira y cuando hablamos de la construcción social de la mirada, es ineludible la variación histórica de regímenes de visibilildad y de legitimidad de las miradas sobre el mundo o, dicho de otro modo, la legitimidad para imponer y naturalizar ciertas miradas como puntos de vista hegemónicos o al menos ampliamente aceptados en la sociedad.

Sin embargo, esta distinción entre el ver y el mirar adolece de algunas debilidades que podrían sintetizarse en una frase: no existe ver sin mirar ni mirar sin ver, es decir, no hay acto físico en el globo ocular desconectado de las impresiones que genera en el cerebro (i.e. en la mente) ni mirar intencionado sin los procesos ópticos de orden anatómico. Para saldar esta dicotomía, estudios más recientes están desarrollando la categoría de mirada y, a partir de ello, están revisitando temas ya muy estudiados; entre ellos -y en relación con los intereses de este artículo-, cabe mencionar el de las expediciones científicas.

En las expediciones y la literatura de viajes, la construcción social de la mirada durante el siglo XIX y la permisividad para ciertas formas de subjetividad significó también la construcción de un sujeto que mira. Y ese sujeto que miraba era un hombre, blanco y occidental, y su mirada era, en palabras de Cosgrove, "falocéntrica, colonista y calculadora, voyeurista, dominante y explotadora” (Cosgrove, 2002: 4). Y va más allá:

Los ojos imperiales lo veían todo con lentes europeas, tanto de manera real como metafórica. Las tecnologías de la visión que transforman la Europa rural 
en paisaje se aplican a estos "otros" espacios. Se educó a soldados, marineros, exploradores, así como a artistas en las técnicas de observación, topografía y bosquejo de paisajes. Sus representaciones eran poderosos elementos para enviar conocimientos de los países exóticos "distintos" de los centros imperiales que elaboraban y reforzaban las geografías imaginativas (...). Cuando se estudian desde un punto de vista crítico, se pone de manifiesto que estas imágenes del paisaje son creaciones híbridas que reflejan el encuentro de convenciones visuales elaboradas en los países de origen y la necesidad de dejar constancia de las formas, fenómenos y ambientes que en realidad se vieron para las que esas convenciones fueron un vehículo de expresión inadecuado (Cosgrove, 2002: 87).

Y no hay que desmerecer el hecho de que esos viajeros escribieron, publicaron y realizaron diversas operaciones narrativas (conferencias, cursos, columnas periodísticas) que diseminaron con eficacia ese tipo de mirada. $Y$ aunque es cierto que la mayoría de esos sujetos fueron hombres, también hubo viajeras pero, como se sabe, sus discursos no resultaron $\tan$ influyentes. ${ }^{11}$

Los estudios postcoloniales, feministas y activistas no sólo pusieron en cuestión esa hegemonía del sujeto observador sino que enfatizaron la importancia y la necesidad de analizar los modos de ver de diversos grupos sociales, con sus especificidades, tensiones y luchas de conflicto. Así comenzó a desmontarse ese sujeto arquetípico cuya mirada se suponía monolítica y emergió una multiplicidad de miradas que, a su vez, dan cuenta del complejo entramado social en el que las prácticas de ver, mirar y observar tienen diferentes agencias y diversos grados de influencia en la sociedad (y, por supuesto, también en la historiografía).

Los debates de hoy en día asumen que existe una multiplicidad y pluralidad de miradas. La distinción entre ver y mirar ya no puede reducirse a lo óptico vs. lo cultural. La cuestión de la mirada es una faceta de las tensiones de nuestro tiempo: no sólo en la pretendida objetividad de las ciencias, sino incluso en la subjetividad de la vida cotidiana, las miradas están sujetas a regímenes de visibilidad o, en términos de José Luis Brea, regímenes escópicos:

Un conjunto de condiciones de posibilidad -determinado técnica, cultural, política, histórica y cognitivamente- que afectan a la productividad social de los "actos de ver", como (...) un sistema fiduciario de presupuestos y convenciones de valor y significancia, que definen el régimen particular de creencia que con las producciones resultantes de dichos actos es posible establecer (Brea, 2007: $150-151){ }^{12}$

El mirar también tiene su historia en la tradición de los saberes geográficos. Por razones de espacio nos limitaremos a señalar una de las que consideramos más significativas: el concepto de paisaje y su impacto con las prácticas de observación en el trabajo de campo.

11 Diversos trabajos procuran recuperar esas otras voces y miradas que fueron invisibilizadas en su tiempo y aún varias décadas después. Algunos de esos trabajos: Blunt y Rose, 1999; García Ramón, 2016; McEwan, 2000; Secor, 1999 y Servelli, 2014. 
Partiremos de una definición deliberadamente vaga y amplia: el paisaje es la expresión sensible (a menudo tomado como sinónimo de expresión visible) de la acción de los hombres sobre la naturaleza, de una organización social y de formas de producción históricamente variables que dejan huellas (rugosidades, diría Milton Santos) en su aspecto actual, es decir, el paisaje es la expresión visible del espacio geográfico. El origen de la concepción visual de paisaje está muy ligada a la historiografía en el campo de las artes, la estética y la filosofía, que tradicionalmente atribuían al ascenso de Petrarca al monte Vertoux desde donde alcanzaba un punto de vista elevado que le permitía la contemplación, en el sentido visual y en el sentido reflexivo, del espacio que tenía ante sus ojos. El punto de vista que requiere la visión panorámica aleja al observador, lo saca del espacio, transforma el espacio en paisaje. En el mirar, "las relaciones entre el paisaje y el espectador están doblemente distanciadas, primero por la distancia física entre punto de observación y superficie, y segundo por la separación entre el ojo (cuerpo) y la imaginación (mente)". 13

Ahora bien: independientemente de las concepciones de paisaje que se maneje (y, por cierto, entre los geógrafos han variado notablemente a lo largo del tiempo y en distintas comunidades académicas), la vista ha formado parte de todas ellas. Recientemente, varios geógrafos y antropólogos han adaptado el término propuesto por Gilles Deleuze (1969) de sentido háptico de la vista (en oposición al tradicional sentido óptico de la vista, entendido como un ejercicio de la vista que ya no es óptico, es decir, de visión distante. Al contrario, el ejercicio háptico o la vista háptica es la vista cercana que capta la forma y el fondo sobre el mismo plano, igualmente cercano (Deleuze, 1969: 204-105)) en el que se aniquila esa distancia que presuponía la observación del paisaje. Si bien Deleuze estaba pensando en la pintura, la idea de visión háptica aplicada a la geografía redefine el modo de aprehender el espacio con el cuerpo, con todos los sentidos. El antropólogo Tim Ingold afirma que

El paisaje [...] no es una totalidad sobre la que usted o quien sea pueda llevar la mirada; es más bien el mundo en cuyo interior nos posicionamos adoptando un punto de vista sobre lo que nos rodea. Y es en el contexto de dicha implicación atenta al paisaje, como la imaginación humana trabaja, elaborando ideas sobre él. Pues el paisaje, para tomar una frase de Merleau-Ponty, no es tanto el objeto cuanto la patria de nuestros pensamientos (Ingold, 2011: 207).

Se habla de geografia háptica, sobre todo, para reivindicar ciertos métodos etnográficos en el trabajo de campo del geógrafo, que no sólo recuperen lo visual sino también los otros sentidos y lo visceral, también el movimiento y las impresiones. ${ }^{14}$

Al tratar la visión como un sentido que sólo funciona en colaboración con los otros, la cuestión de la mirada no sólo es háptica: también es sonora y olfativa (como demuestra Alain Corbain en El perfume o el miasma).

En congruencia con esta resignificación del concepto de paisaje, las prácticas del trabajo de campo de los geógrafos también fueron variando y superponiendo distintos modos de ver: mientras que el método vidaliano de trabajo de campo consistía básicamente en

13 Con otras palabras, Denis Cosgrove postuló la misma idea de distancias. Véase Cosgrove, 2002: 72. 
ver con la vista, los métodos etnográficos que se volvieron dominantes en los trabajos de campo de los geógrafos, en las últimas dos décadas, conciben la mirada en ese otro sentido integral, corpóreo, multisensorial (Zusman, 2011).

Decía Roland Barthes: "yo quisiera una historia de las miradas" (2006: 40). Luego de años, décadas y siglos debatiendo sobre el ojo, la óptica, el sentido de la vista, los instrumentos de observación, la mecanicidad de la producción de imágenes y todos los dispositivos ópticos que modificaron y modifican la visión natural del ojo humano, premonitoriamente Barthes expresaba en forma de deseo personal lo que hoy es una necesidad y un compromiso: debatir y analizar los modos en que miramos.

\section{Conclusiones. De la contemplación a las miradas críticas}

En los siglos XVI y XVII, una generación de jóvenes tales como Copérnico, Kepler y Galileo inventaron la realidad objetiva asimilando las disciplinas escolásticas de la astronomía (inculcando la prueba analítica en materia de cosmología bajo la forma de modelos matemáticos) y de la física (inculcando la prueba dialéctica sobre las mismas cuestiones, a partir de todo el saber movilizable para sus propósitos). La distinción entre lo real y un espacio de modelización fue sacrificado en función de esta fusión y constituyó desde entonces una fuente permanente de confusión en la explicación (Jorion, 2009).

En el curso del siglo XVIII, la observación se transformó en una herramienta de conjetura, un modo de excluir algunas hipótesis explicativas y ensayar otras nuevas, lo que llevó a redefinir la propia idea de observación y experimento. En contraste con la tendencia dieciochesca de separar tajantemente observación y conjetura, los manuales de observación científica que aparecieron hacia mediados del siglo XVIII insistían en que la observación era un modo de razonar y no sólo de coleccionar experiencias; y así como se fue instalando la idea de que observar con pre-juicios a favor o en contra de algún sistema explicativo era algo deplorable, también terminó por aceptarse que no era posible observar sin ideas (Daston, 2011).

El análisis del desarrollo técnico de instrumentales que modificaron la visión, el sentido de la vista y los modos de mirar pusieron en cuestión los métodos de aproximación a esa supuesta realidad objetiva e incluso más tarde cuestionarían los presupuestos ontológicos de tal realidad objetiva. Por eso, la cuestión del sentido de la vista y las técnicas de observación en las ciencias modernas no puede agotarse en la enumeración de los progresos tecnológicos porque esos instrumentos de precisión que le fueron dando legitimidad al conocimiento científico del mundo por encima de otras formas de conocer apoyados en prácticas cuantitativas que prometían neutralidad son, en realidad, tecnologías de poder" (en el sentido foucaultiano) que redefinen, al mismo tiempo, la percepción del sujeto, la representación de la naturaleza y los principios subyacentes al orden social. $Y$ ese arsenal técnico de producción de imágenes científicas logró consagrar una estandarización de la imaginería visual durante el siglo XIX que "debe entenderse, entonces, no sólo en el contexto de las nuevas formas de reproducción mecánica, sino también en relación a un proceso más amplio de normalización y sujeción del espectador" (Crary, 1990: 36).

Ahora bien: ¿̇por qué es importante reflexionar sobre el funcionamiento de las imágenes? Por un lado, porque las imágenes científicas participan de la construcción de 
una cultura visual que trasvasa las instituciones académicas y crea sentido común sobre el mundo (tomemos como ejemplo apenas un caso sencillo, el del esquema del sistema solar y la aceptación generalizada de que vivimos en una galaxia heliocéntrica). Pero además, hay una cuestión política que le da relevancia a las cuestiones aquí planteadas: como dice Monique Sicard "las industrias del conocimiento se enmarañan íntimamente con las de creer y su corolario: las de hacer creer. Cuanto más se afirma -en primer término- el desconocimiento sobre los dispositivos de visión, mejor se ejerce -en segundo lugar- la función política de las imágenes. Cuanto más se proclama indicando su neutralidad, mejor transmiten sus puntos de vista e instalan sus ficciones como si fueran hechos" (1998: 11)

En este artículo propusimos traer a colación los debates y las argumentaciones sobre el sentido de la vista y las técnicas de observación y registro en la ciencia moderna para plantear un dilema que, consideramos, sigue abierto: ¿cómo deberían articularse las técnicas y los sentidos para reflexionar ética, sistemática y críticamente para responder a las demandas sociales que se le hacen a la ciencia? 


\section{Q Bibliografía}

» Arnheim, R. (1960). El pensamiento visual. Buenos Aires: EUDEBA.

》 Aumont, J. (2013 [1990]). La imagen. Barcelona: Paidós.

》 Barthes, R. (2006). La camera lúcida. Barcelona: Paidós.

» Benjamin, W. (2015). Estética de la imagen. Buenos Aires: La marca editora.

»Berger, J. (1998). Mirar, Buenos Aires: Ediciones de la Flor.

» Berger, J. (2004). Modos de ver. Barcelona: Gustavo Gili.Blunt, A y Rose, G (Comps.). (1999). Writing women and space: colonial and postcolonial geographies. Nueva York y Londres: Guilford Press.

» Bourguet, M. N., Christian Licoppe, H. y Otto S. (Eds.). (2002). Instruments, Travel and Science: Itineraries of Precision from the Seventeenth to the Twentieth Century (Routledge Studies in the History of Science, Technology and Medicine). London; New York: Routledge.

»Brea, J. L. (2007). Cambio de régimen escópico: del inconsciente óptico a la eimage. Estudios visuales: Ensayo, teoría y crítica de la cultura visual y el arte contemporáneo, 4, 146-163.

» Bredekamp, H. (2008). Les coraux de Darwin. Premiers modèles de l'evolution et tradition de l'histoire naturelle. París: Les press du réel.

» Corbain, A. (1987). El perfume o el miasma. México: D.F. Fondo de Cultura Económica.

" Cosgrove, D. (2002). Observando la naturaleza: el paisaje y el sentido europeo de la vista. Boletín de la AGE, 34, 63-89.

» Crary, J. (1990). Las técnicas del observador. Visión y modernidad en el siglo XIX. Murcia: Cendeac.

»Crosby, A. (1988). The Measure of Reality. Quantification and Western Society, 12501600. Cambridge: Cambridge University Press.

»Curnier, J.P. (2009). Montrer l'invisible. Écrits sur l'image. Actes Sud, Éditions Jacqueline Chambon, Rayon Philo.

»Daston L. y Galison P. (1992). The Image of Objectivity. Representations, 40, Special Issue: Seeing Science Autumn.

»Daston, L. y Galison P. (2007). Objectivity. New York: Zone Books.

» Daston, L. (2011). The Empire of Observation, 1600-1800. En D. Lorraine y E. Lunbeck, Histories of Scientific Observation. Chicago: The University of Chicago Press.

»Deleuze, G. (1969). Logique du sens. Paris: Les Éditions de Minuit.

”Deleuze, G. (1999). Michel Foucault, filósofo. Barcelona: Gedisa.

"Deleuze, G. (2007). Pintura. El concepto de diagrama. Buenos Aires: Cactus.

»Didi-Huberman, G. (2010). Atlas. ¿Cómo llevar el mundo a cuestas? Museo Nacional 
Centro de Arte Reina Sofía, Museum für Neue Kunst, Sammlung Falckenberg: Madrid: Karlsruhe y Hamburgo.

»Dubois, P. (1986). El acto fotográfico. Barcelona: Paidós Comunicación.

"Edgerton, S- Y. Jr. (1975). The Renaissance Rediscovery of Linear Perspective. MPublishing, University of Michigan Library.

》Foucault, M. (1968). Las palabras y las cosas. Buenos Aires: Siglo XXI Editores.

»Fodor, J. y Pylshyn, Z. (2002). How Direct is Visual Perception? Some Reflections on Gibson's "Ecological Approach". En Vision and Mind. Selected Readings in the Philosophy of Perception (pp. 167-228). Massachussets: Massachussets Insitute of Technology.

" Galileo G. (2010). Diálogo sobre los dos máximos sistemas del mundo, ptolemaico y copernicano. Madrid: Editorial Maxtor.

» García Ramón, M. D. (2016). Geografía del género y los espacios de encuentro colonial: una nueva mirada a las narrativas de viaje. Debate feminista, 51, 50-62.

» Gibson, J. (1950). The Perception of the Visual World. Boston: Houghton Mifflin.

» Gibson, J. (1950). La percepción del mundo visual. Buenos Aires: Ed. Infinito.

" Gibson, J. (2002). A Theory of Direct Visual Perception. En A. Noë y E. Thompson (Eds.), Vision and Mind. Selected Readings in the Philosophy of Perception (pp. 7790). Massachussets: Massachussets Insitute of Technology.

" Godlewska, A. (1995). Map, Text and Image. The Mentality of Enlightened Conquerors: A New Look at the Description de l'Egypte Transactions of the Institute of British Geographers, 20(1).

" Gregory, R. (2002). Perceptions as Hypothesis. En A. Noë y E. Thompson (Eds.), Vision and Mind. Selected Readings in the Philosophy of Perception. Massachussets: Massachussets Insitute of Technology.

" Guenancia, P. (2009). Le regard de la pensée. Philosophie de la représentation. París, Presses universitaires de France.

» Harley, J. B. (2001). La nueva naturaleza de los mapas. Ensayos sobre la historia de la cartografía. México: Fondo de Cultura Económica.

»Ingold, T. (2011). The Perception of the Environment: Essays on Livelihood, Dwelling and Skill. Londres: Routledge.

»Ings, S. (2008). A Natural History of Seeing. The art and science of visión. Nueva York, Londres: WW Norton \& Company.

"Ivins, W. (1985). La rationalisation du regard. Culture technique. Centre de recherche sur la culture technique, Neuilly-sur-Seine

» Jones, C. y Galison, P. (Eds.). (1998). Picturing Science, Producing Art. Nueva York, Londres: Routledge.

» Jorion, P. (2009). Comment la vérité et la réalité furent inventées. París: Gallimard.

"Keller, S. (1998). Sections and views: visual representation in eighteenth-century earthquake studies. En The British Society for the History of Science (pp. 129-159), 31(2).

"Latour, B. (1987). La science en action. Introduction à la sociologie des sciences. París: La Découverte. 
» Latour, B. (1990). Drawing things together. En M. Lynch y S. Woolgar (Eds). Representation in scientific practice (pp. 19-68). MIT Press Ed., Cambridge: Mass., MIT Press.

» Latour, B. (1996). Les 'vues' de l'esprit. Une introduction à l'anthropologie des sciences et des techniques. En M. Akrich y M.Callon (Eds.), Sociologie de la traduction. Textes fondateurs (pp. 33-70). Paris: Presses de l'Ecole des Mines de Paris.

" Lenoir, T. (1998). Inscription practices and materialities of communication. Inscribing Science: Scientific Texts and the Materialities of Communication (pp. 119), Standford: Standford University Press.

» Lynch, M. and Woolgar S. (Eds). (1990). Representation in scientific practice. MIT Press Ed., Cambridge, Mass: MIT Press.

» Lynch, M. y Woolgar S. (1990). Introduction: sociological orientations to representational practice in science. En M. Lynch y S. Woolgar (Eds), Representation in scientific practice (pp. 2-18). MIT Press Ed., Cambridge, Mass.: MIT Press.

» Martin, J. (1992). Scopic Regimes of Modernity. En Force Fields, Between Intellectual History and Cultural Critique (pp. 114-133). Nueva York: Routledge.

» Martyn J. y Allestry, J. A. (1989 [1665]). Micrografía, o algunas descripciones fisiológicas de los cuerpos diminutos realizadas con cristales de aumento con observaciones y disquisiciones sobre ellas. Madrid: Alfaguara.

» Mcewan, C. (2000). Gender, Geography and Empire. Victorian women travellers in West Africa. Aldershot: Ashgate.

» Moretti, F. (2005 [2007]). Graphs, maps, trees. Abstract models for literary history. Londres, Nueva York: Verso.

» Moxey, K. (2009). Los estudios visuales y el giro icónico. A/V Revista Artes Visuales, 6, 8-17.

» Moser, S. (1996). Visual Representation in Archaeology: Depicting the MissingLink in Human Origins (184-214). En B. Baigri (Ed.), Picturing Knowledge. Historical and Philosophical Problems Concerning the Use of Art in Science. Toronto, Buffalo: University of Toronto Press. London Series, Toronto studies in philosophy.

» Noë, A. y Thompson, E. (Eds.). (2002). Vision and Mind. Selected Readings in the Philosophy of Perception. Massachussets: Massachussets Insitute of Technology.

» Paterson, M. (2009). Haptic geographies: ethnography, haptic knowledges and sensuous dispositions. Progress in Human Geography, 33(6), 766-788.

»Penhos, M. (2005). Ver, conocer, dominar. Imágenes de Sudamérica a fines del siglo XVII. Buenos Aires: Siglo XXI.

» Pocock, D. C. D. (1981). Sight and Knowledge. Transactions of the Institute of British Geographers, New Series, 6(4), 385-393. Blackwell: Royal Geographical Society (with the Institute of British Geographers).

» Pomián, K. (1998). Vision and Cognition. En C. Jones y P. Galison (Eds.), Picturing Science, Producing Art (pp. 211-231). Nueva York, Londres: Routledge.

» Sauvageot, A. (1994). Voir et savoirs. Esquisse d'une sociologie du regard. París: Presses Universitaires de France.

» Schickore, J. (2007). The Microscope and the Eye: A History of Reflections, 1740- 
1870. Chicago: The University of Chicago Press.

»Secor, A. (1999). Orientalism, gender and class in Lady Mary Wortley Montagu's Turkish Embassy Letters. Ecumene, 6(4), 375-398.

» Servelli, M. (2014). Paisajes de la patria para mujeres que viajan solas. La casa argentina de Ada Martín Elflein. En M. Sierra, Geografías Imaginarias. Espacios de resistencia y crisis en América Latina (pp. 385-415). Santiago de Chile: Cuarto Propio.

» Seymour, K. (2007). Teaching and learning: Maps as metaphor. En Enhancing Higher Education, Theory and Scholarship, Proceedings of the 30th HERDSA Annual Conference (pp. 510). Adelaide, 8-11 julio.

» Shapin, S. (2000). La Revolución Científica. Una interpretación alternativa. Barcelona: Paidós.

„ Sicard, M. (1998). La fabrique du regard. Images de science et appareils de vision (XVe- XXe siècle). Paris: Editions Odile Jacob - Le champ médiologique.

» Silverman, K. (1996). El umbral del mundo visible. Madrid: Ediciones Akal.

»Snyder, J. (2007). Map projections in the Renaissance. En D. Woodward (Ed.), The History of the Cartography. Cartography in the European Renaissance, Vol. 3 (pp. 365-380). Chicago, Londres: The University Chicago Press.

»Sontag, S. (1973 [2005]). Sobre la fotografía. Buenos Aires: Alfaguara.

» Sturken, M. y Cartwright, L. (Coords.). (2001). Practices of looking. An introduction to visual culture. Nueva York: Oxford University press.

» Tufte, E. (1990). Envisioning Information. Cheshire (Connecticut): Graphic Press.

" Turchi, P. (2004). Maps of the imagination: the writer as cartographer. San Antonio (Texas): Trinity University Press.

»Zusman, P. (2011). La tradición del trabajo de campo en Geografía, Geograficando. Revista de Estudios Geográficos, (7), 10-22.

Carla Lois / carlalois054@gmail.com Licenciada en Geografía y Doctora en Filosofía y Letras, ambos por la Universidad de Buenos Aires. Investigadora Independiente en el CONICET. Profesora adjunta en Teorías Contemporáneas en Geografía en la Facultad de Filosofía y Letras de la Universidad de Buenos Aires. Sus investigaciones versan sobre la historia de la cartografía y a los estudios visuales de imágenes asociadas al pensamiento científico. Coordinadora del Grupo de Historia y Epistemología de las Cartografías e Imágenes Técnicas.

Malena Mazzitelli Mastricchio / mastricchiomalena@gmail.com

Doctora en Geografía de la Universidad de Buenos Aires y becaria post-doctoral de CONICET. Profesora de la Universidad Autónoma de Entre Ríos y de la Universidad Nacional de la Plata. Trabaja temas de historia de la cartografía argentina de los que publicó diversos artículos y ha organizado distintos eventos y reuniones científicas relacionadas con la temática. 